\title{
Autoantibodies found after thymectomy in a patient later developing myasthenia gravis
}

\author{
JOHN H. KERR ${ }^{1}$, CARLOS G. DURAN, HELEN THOMAS, AND RALPH WRIGHT \\ From the Thoracic Surgical Unit, Churchill Hospital, Oxford, and the Nuffield Departments of Anaesthetics \\ and Medicine, Radcliffe Infirmary, Oxford
}

An autoimmune basis for myasthenia gravis has been suggested (Simpson, 1960; 1964), and autoantibodies have been found in some patients with the disease (Strauss, Seegal, Hsu, Burkholder, Nastuk, and Osserman, 1960; Marshall and White, 1961; Beutner, Witebsky, Ricken, and Adler, 1962; van der Geld, Feltkamp, van Loghem, Oosterhuis, and Biemond, 1963). There have been several reports recently linking thymic lesions with immunological phenomena (Burnet and Mackay, 1962; Miller, 1963), and the association between thymoma and myasthenia gravis is well known. Several cases have been reported in which myasthenic symptoms appeared after removal of a thymic neoplasm (Rowland, Aranow, and Hoefer, 1957; Ellman and Hodgson, 1958).

This report concerns a woman whose serum was found to be strongly positive for antinuclear factor and anti-muscle antibodies six months after removal of a thymoma and three months before she developed clinical myasthenia gravis.

\section{CASE REPORT}

The patient, a 69-year-old housewife (R.I. Number 350855), was radiographed routinely following the discovery of a case of tuberculosis in her family. The radiographs showed a rounded lesion in the anterior mediastinum to the left of the midline. On admission in October 1963 the patient had no complaints except slight shortness of breath on exertion. In 1957 she had had a cerebrovascular accident, which had caused a transient left hemiparesis. On examination she was a frail-looking woman with no abnormal physical signs except for slightly brisker reflexes in the left leg.

A bronchoscopy was performed under general anaesthesia using thiopentone and suxamethonium, $100 \mathrm{mg}$. Appearances were normal and she recovered uneventfully from the anaesthetic.

Three days later a tumour was excised from the anterior mediastinum through a left thoracotomy. The patient was given pethidine, $50 \mathrm{mg}$., and atropine, $0.4 \mathrm{mg}$., as premedication. Forty minutes later anaesthesia was induced with thiopentone, $350 \mathrm{mg}$., followed by suxamethonium ${ }^{1}$ Present address: Department of Anaesthetics, Southampton General Hospital, Southampton.
$50 \mathrm{mg}$., to facilitate intubation of the larynx. Anaesthesia was continued with nitrous oxide in a circle absorber circuit with a leak. When spontaneous respiration had recommenced, d-tubocurarine, $21 \mathrm{mg}$., was given intravenously and artificial ventilation begun. Thoracotomy was performed and a firm tumour, $4 \mathrm{~cm} . \times 3 \mathrm{~cm}$., situated in the mediastinal fat at the anterior aspect of the pericardial sac, was easily excised. The possibility of the tumour being a thymoma was suggested and the histology later confirmed this. At the end of the operation, one hour later, atropine $1.2 \mathrm{mg}$., followed by neostigmine, $2.5 \mathrm{mg}$., were injected intravenously. The patient coughed and opened her eyes while the trachea was being aspirated, but her respirations were inadequate and there was marked tracheal tug. Artificial ventilation was recommenced using air from an Oxford inflating bellows. Intravenous injections of bemegride, $50 \mathrm{mg}$., and nalorphine, $10 \mathrm{mg}$., were given to counteract any respiratory depressant effect of the pethidine, but there was no improvement. Atropine $0.6 \mathrm{mg}$. followed by neostigmine $1.25 \mathrm{mg}$. were also without effect. The systolic blood pressure remained at $100 \mathrm{~mm} . \mathrm{Hg}$ throughout.

At this stage it appeared that artificial respiration would be required for several hours; the patient was taken back to the ward and intermittent positive pressure respiration continued with a Radcliffe respirator. Twelve hours after the operation it was possible to remove the endotracheal tube. With encouragement, she coughed well and maintained a good colour on humidified oxygen. The respiratory rate was 20 per minute and the pulse and blood pressure were normal.

Peak expiratory flow rate and vital capacity were measured three-hourly for the next 10 days to detect whether the patient was developing myasthenic weakness. Readings were also taken before and after injections of atropine $0.6 \mathrm{mg}$. and neostigmine $2.5 \mathrm{mg}$. as a test for subclinical weakness. There was no significant change in the readings. Further convalescence was uneventful and the patient was discharged 11 days after operation.

On readmission in April 1964, the patient did not think her condition had changed since before the operation. There were no symptoms suggesting myasthenia gravis and no new abnormal signs, though the mild residual signs on the left side from the stroke were more noticeable. Blood calcium and electrolytes were normal.

The patient's sensitivity to non-depolarizing muscle relaxants was tested, gallamine rather than curare being employed to reduce the probability of respiratory distress 
(Dundee, 1951). The patient was starved for some hours and adequate means of artificial respiration were at hand. An intravenous injection of atropine, $0.6 \mathrm{mg}$., was followed after five minutes by one of gallamine, $5 \mathrm{mg}$. Within one minute the patient's eyes closed and she could not open them. She was unable to swallow, raise her head, or speak, though there was no obvious respiratory distress or cyanosis. Neostigmine, $1.75 \mathrm{mg}$., was given immediately and within three minutes the patient was able to open her eyes, speak and swallow normally, and was breathing more deeply. Ten minutes later, after a total dose of $2.5 \mathrm{mg}$. neostigmine, her vital capacity was $1,800 \mathrm{ml}$. and peak flow was 155 litres per minute. Further readings were taken for the next 14 hours and remained satisfactory.

The response to stimulation of the ulnar nerve at the wrist was tested using the Medelec nerve stimulator (Wylie and Churchill-Davidson, 1959). At twitch rate of stimulation, no fatigue was shown and there was no detectable post-tetanic facilitation. A test on a hand dynamometer next showed no organic weakness and electromyography performed a day later was essentially normal. A specimen of serum was taken at this stage for subsequent immunological tests.

In July 1964 the patient was referred to the neurological clinic complaining of diplopia, difficulty in speaking clearly, and neck muscle weakness. These symptoms became worse as the day progressed and were relieved by rest. A diagnosis of myasthenia gravis was made and treatment with pyridostigmine commenced. When seen again in September 1964 the patient's symptoms were more generalized, though they were improved by taking neostigmine or pyridostigmine. A further specimen of serum was taken on this occasion.

\section{IMMUNOLOGICAL TESTS}

The specimens of serum were tested for antinuclear factor and antibodies to skeletal muscle. Calf thymus smears (Widelock, Gilbert, Siegel, and Lee, 1961) and sections of human thyroid were used when testing for antinuclear factors by the indirect fluorescent antibody technique (Weller and Coons, 1954). Human skeletal muscle, obtained at operation, and rat diaphragm were used when testing for antibodies to muscle.

Very strong nuclear fluorescence, indicating the presence in the serum of an antinuclear factor, was seen with both specimens of serum. In addition, binding of gamma globulin to both skeletal muscle and rat diaphragm was demonstrated.

When serial dilutions of both specimens of serum were tested for antinuclear factors and for antibodies to skeletal muscle, no consistent difference in titre was found. Paper electrophoresis of both specimens showed a normal protein pattern and were closely similar.

\section{DISCUSSION}

In 1957 Rowland et al. were able to collect reports of 10 patients who had developed myasthenia gravis after operations in which thymic neoplasms had been excised. Since then six other cases have been described or mentioned (Roe, 1957; Madonick,
Rubin, Levine, and Karliner, 1957; Ehrenreich and Allen, 1958; Ellman and Hodgson, 1958; Bernatz, Harrison, and Clagett, 1961; Hasner and Westengård, 1963). These small numbers probably do not represent the true incidence of this sequence of events, since, of the eight patients treated surgically for thymic neoplasms in the Thoracic Surgical Unit since 1950, two have developed myasthenia after operation. Apart from the case described by Roe, all the patients who developed myasthenia retained some thymic tissue after operation. Either a malignant tumour was incompletely excised or the thymus itself was not touched when a benign tumour was removed, as in our case.

The time of appearance of the myasthenic symptoms varied from immediately after operation to five years later. The patients described can be placed in three groups. First, are those who, in retrospect, were seen to have shown mild myasthenic symptoms before operation (Rowland et al., 1957; Ellman and Hodgson, 1958). In the second group, myasthenia appeared immediately after operation and there was a lasting weakness which responded to anticholinesterases (Rowland et al., 1957; Hasner and Westen-o gård, 1963). Patients in both groups presented aథ̣. operation as prolonged respiratory insufficiency particularly if curare had been employed as muscle relaxant.

The third group included all those patients in whom the myasthenic symptoms had come on after symptom-free interval varying from a few weeks to several years (Roe, 1957; Madonick et al., 1957을 Ehrenreich and Allen, 1958). In none of the patients in this last group was there any mention of postoperative apnoea or anything to suggest that they were hypersensitive to curare. In our case, and in the patient described by Ellman and Hodgson, there was hypersensitivity to curare at operation followed by an asymptomatic period lasting several months. Prolonged weakness requiring anticholinesterase therapy appeared in both cases a few weeks after a positive gallamine sensitivity test.

Much recent work has indicated that the thymus plays an important part in the immunological mechanism of the body (Burnet and Mackay, 1962; Miller, 1963). Histological changes in this organ have been reported in association with 60 to $70 \%$ of myasthenics (Marshall and White, 1961) and thymectomy has been employed with varying success as a method of treating myasthenia for many years (Simpson, 1960). Two main types of antibodies have been described in patients with myasthenia gravis: those against muscle and those against nuclear components. Strauss et al. (1960), Beutner et al. (1962), and van der Geld et al. (1963) all demonstrated a globulin which became fixed to muscle 
with binding of complement in approximately $40 \%$ of myasthenic sera. Antibodies to nuclear factors appear in a rather smaller proportion of sera mostly taken from patients with active myasthenia. There have been several cases of myasthenia and systemic lupus erythematosus in the same patient, some associated with a thymoma (Alarcón-Segovia, Galbraith, Maldonado, and Howard, 1963). White and Marshall (1962) found antinuclear factor in the sera of six out of 16 active myasthenics, and of the six with positive results, two had lupus erythematosus. In Feltkamp's series (Feltkamp, van der Geld, Kruyff, and Oosterhuis, 1963), however, in which 11 out of 103 cases showed antinuclear factor strongly, it was stressed that all the antinuclear factor positive sera showed negative indirect L.E. cell tests.

In view of the suggested auto-immune aetiology of myasthenia gravis, the finding of a strongly positive reaction for antinuclear factor in the serum of a patient three months before the appearance of clinical symptoms is of interest. The observation that the autoantibodies were present six months after removal of a benign thymoma may also be important. The significance of antinuclear factors in the pathogenesis of disease is uncertain. However, the fact that they do not produce lesions in healthy recipients after passive transfer (Bencze, Cserhati, Kovacs, and Tiboldi, 1958; Beck and Rowell, 1963) suggests they are of secondary importance. In this context, it is of interest that in the present case there was no significant change in the titre of antinuclear antibodies or of antibodies to skeletal muscle during the period in which clinical evidence of myasthenia gravis developed. Further studies will be required to assess the significance of these results.

We wish to thank Mr. C. Grimshaw, Dr. R. BryceSmith, and Dr. J. M. K. Spalding for permission to report their case and for their interest and encouragement. We are also indebted to Dr. G. Rushworth for performing the electromyographic studies.

\section{REFERENCES}

Alarcón-Segovia, D., Galbraith, R. F., Maldonado, J. E., and Howard, F. M. (1963). Systemic lupus erythematosus following thymectomy for myasthenia gravis. Lancet, 2, 662-665.
Beck, J. S., and Rowell, N. R. (1963). Transplacental passage of antinuclear antibody. Ibid., 1, 134-135.

Bencze, G., Cserhati, S., Kovacs, J., and Tiboldi, T. (1958). Production of L.E. cells in vivo by transfusion of systemic lupus erythematosus plasma. Ann. rheum. Dis., 17, 426-428.

Bernatz, P. E., Harrison, E. G., and Clagett, O. T. (1961). Thymoma: a clinico-pathologic study. J. thorac. Surg., 42, 424-444.

Beutner, E. H., Whitebsky, E., Ricken, D., and Adler, R. H. (1962). Studies on autoantibodies in myasthenia gravis. J. Amer. med. Ass., 182, 46-58.

Burnet, F. M., and Mackay, I. R. (1962). Lymphoepithelial structures and autoimmune disease. Lancet, 2, 1030-1033.

Dundee, J. W. (1951). Gallamine in the diagnosis of myasthenia gravis. Brit. J. Anaesth., 23, 39-41.

Ehrenreich, T., and Allen, A. C. (1958). Myasthenia gravis following extirpation of an asymptomatic thymoma. Cancer (Philad.), $11,173-180$.

Ellman, P., and Hodgson, D. C. (1958). Myasthenia gravis in association with a malignant thymic tumour. Brit. med. J., 1, 626-628.

Feltkamp, T. E. W., van der Geld, H., Kruyff, K.; and Oosterhuis, H. J. G. H. (1963). Antinuclear factor in myasthenia gravis. Lancet, 1, 667.

Hasner, E., and Westengård, E. (1963). Thymomas. Acta chir. scand., 126, 58-65.

Madonick, M. J., Rubin, M., Levine, L. H., and Karliner, W. (1957). Myasthenia gravis developing fifteen months after removal of thymoma. Arch. intern. Med., 99, 151-155.

Marshall, A. H. E., and White, R. G. (1961). Experimental thymic lesions resembling those of myasthenia gravis. Lancet, 1, 1030-1031.

Miller, J. F. A. P. (1963). Role of the thymus in immunity. Brit. med. J., 2, 459-464.

Roe, B. B. (1957). Myasthenia gravis secondary to thymic neoplasm; report of a case in which symptoms developed six weeks after total thymectomy. J. thorac. Surg., 33, 770-775.

Rowland, L. P., Aranow, H., and Hoefer, P. F. A. (1957). Myasthenia gravis appearing after the removal of thymoma. Neurology (Minneap.), 7, 584-588.

Simpson, J. A. (1960). Myasthenia gravis: a new hypothesis. Scot. med. J., 5, 419-436.

(1964). Immunological disturbances in myasthenia gravis with a report of Hashimoto's disease developing after thymectomy. J. Neurol. Neurosurg. Psychiat., 27, 485-492.

Strauss, A. J. L., Seegal, B. C., Hsu, K. C., Burkholder, P. M., Nastuk, W. L., and Osserman, K. E. (1960). Immunofluorescence demonstration of a muscle binding, complementfixing serum globulin fraction in myasthenia gravis. Proc. Soc. exp. Biol. (N.Y.), 105, 184-191.

van der Geld, H., Feltkamp, T. E. W., van Loghem, J. J., Oosterhuis, H. J. G. H., and Biemond, A. (1963). Multiple antibody production in myasthenia gravis. Lancet, 2, 373-375.

Weller, T. H., and Coons, A. H. (1954). Fluorescent antibody studies with agents of vericella and herpes zoster propagated in vitro. Proc. Soc. exp. Biol. (N.Y.), 86, 789-794.

White, R. G., and Marshall, A. H. E. (1962). The autoimmune response in myasthenia gravis. Lancet, 2, 120-123.

Wylie, W. D., and Churchill-Davidson, H. C. (1959). A Practice of Anaesthesia, p. 118. Lloyd-Luke, London.

Widelock, D., Gilbert, G., Siegel, M., and Lee, S. (1961). Fluorescent antibody procedure for lupus erythematosus: comparative use of nucleated erythrocytes and calf thymus cells. Amer. $J$. publ. Hlth. 51, 829-835. 